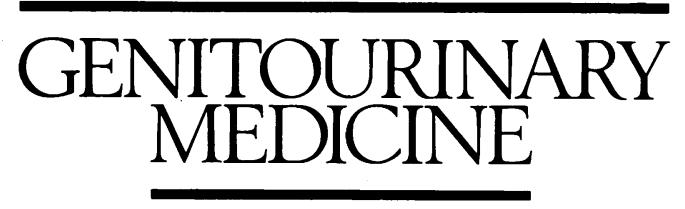

Early warning

From 1998 the title of

Genitourinary Medicine

will become

\title{
Sexually Transmitted Infections
}

\section{HSV type specific antibody tests: patients are ready, are clinicians?}

Genital herpes infections continue to increase. In the United Kingdom, HSV-2 seroprevalence is $11 \%$. In the United States, HSV-2 seroprevalence has risen from $16 \%$ in 1978 to $22 \%$ in 1990 -a $31 \%$ increase. The greatest increase in incidence is in white people between 19 and 35 years of age. In Europe and the United States, 30\% to $60 \%$ of clients attending STD clinics are HSV-2 seropositive In all populations studied, whether of high or low HSV-2 prevalence, the majority of genital HSV-2 infections are unrecognised by patients or clinicians. ${ }^{1-3} \mathrm{~A}$ number of studies also suggest that source partners in most transmission events (including mother to infant transmission) are unaware that they have genital herpes. ${ }^{4-7}$ Clearly, undiagnosed genital herpes infections are the major factor in fuelling the genital herpes epidemic. The most practical and common method for identifying silent virus carriers is testing for serum antibodies. Accurate, HSV type specific serology methods have been available in a number of research laboratories in Scandinavia, ${ }^{8}$ the United States, ${ }^{910}$ Australia, ${ }^{11} 12$ and the United Kingdom ${ }^{13}$ for a number of years and the technology for wide commercial distribution of these tests has existed for over a decade. Yet, in our opinion, companies have been reluctant to invest in type specific HSV test development because clinicians have shown little interest in diagnosing subclinical genital herpes.

Why is this? Perhaps the medical and psychosocial consequences of genital herpes infections are not fully appreciated by most clinicians. Perhaps healthcare providers have been fearful of opening a "Pandora's box" of follow up concerns from patients who, in the absence of appropriate testing, would be otherwise unaware of their infections. The time involved in explaining to each of a potential $30-60 \%$ of STD clinic clients that he/she has a chronic, intermittently transmissible, infection is daunting. The personal aspects of answering questions such as "How did I acquire this infection?"; "What are my responsibilities regarding my present and future partners?"; or, even,
"What do you mean these symptoms are not due to a treatable yeast infection?" are disconcerting. Unfortunately, medical and scientific information to easily answer such questions is not fully available.

Thus, it is of interest that this issue of Genitourinary Medicine offers three articles related to the patient's viewpoint on genital herpes. ${ }^{14-16}$ In particular, Drs Fairley and Monteiro have offered important insights on the opinions of patients regarding who should be tested and under what circumstances. ${ }^{16}$ Their article, "Patient attitudes to type specific serological tests in the diagnosis of genital herpes' reveals that the majority of genitourinary medicine clinic attendees want to know their HSV serostatus. Further, a scaled response measure revealed that this desire to know was extremely strong in the following, perceived, "high risk" circumstances; having had sex with a partner known to have genital herpes, having symptoms suggestive of genital herpes, and having a partner with first episode genital herpes.

The authors added an interesting twist to the study. Half of those who completed the questionnaires on test desirability did so after reading three pages of information which, as described, appears to have been well crafted to inform, in lay terms, of the risks of having genital herpes, the impact of subclinical infections on transmission, and the treatment options. Given this type of information, respondents were significantly more likely than those given no information to want to know if their partner had been infected with genital herpes (95\% v 87\%). Interestingly, about the same proportion of respondents (90\% of "no information" and $95 \%$ of "information given") would "want to know" (via serology if by no other means) if they had been infected. Strength of desire for the test was very high in a variety of suggested circumstances for testing ranging from screening in pregnancy to having genital symptoms.

This study strongly indicates that patients attending a genitourinary clinic desire testing for HSV-2 antibodies. A 
high proportion (64\%) would expect this test to be part of a routine battery for STDs. Whether these responses are predictive of those of other populations such as those presenting for obstetric care or those presenting to a general medicine clinic requires further study since HSV-1 and HSV-2 seroprevalence and awareness vary widely in these practices and within subpopulations. ${ }^{3717-19}$ The desire for testing and the communications skills to request such testing also will vary with subpopulations.

While patients seem to want "the test," many authorities have struggled with the cost effectiveness of such serological screening. As noted above, a positive test for HSV-2 antibodies will trigger the need for counselling of the patient and, possibly, of the patient's partners, subsequent testing of the partners and so on. Infected patients may wish to begin intermittent suppressive antiviral treatment. Undoubtedly, costs will rise, but can providing appropriate care, care desired by patients according to the Fairley and Monteiro study, be "wrong?" Counselling and treatment costs are balanced by two potential cost saving outcomes. Firstly, accurately diagnosing the myriad of historical or presenting complaints to be genital herpes avoids costly, ineffective, treatment for other infections. Secondly, there is the potential for preventing transmission to a sex partner who might be among those whose infection has moderate to severe morbidity requiring expensive medical and psychosocial support. In large measure, the benefit portion of this type of analysis is weighted towards psychosocial benefits; the satisfaction of providing care, including a possibly unpleasant and time consuming counselling session desired by a basically healthy patient. One population for which cost effectiveness of testing is more obvious is pregnant women who are at risk of acquiring genital herpes just before term..$^{7021}$ The financial burdens and psychosocial costs of neonatal herpes are high for a disease which, for many, could be prevented.

Accurate, easy, type specific HSV serology tests based on those performed for years in research laboratories will be on the market within the year in both the United States and Europe. ${ }^{22} 23$ Pitfalls, however, remain. Firstly, as pointed out by Fairley and Monteiro, no serological test can differentiate between oral and genital HSV-1 infection. Second is the recognition that current tests that report HSV-1 and HSV-2 specific values, are inaccurate. For example, using three commercial kits, we obtained a correct diagnosis for only $33-55 \%$ of patients with culture documented infections of 3-8 weeks' duration; from $38 \%$ to $48 \%$ of these patients would have been given a diagnosis of the wrong virus type. ${ }^{24}$ For those with subclinical infections, these kits correctly typed serum antibodies in as few as $5 \%$ of HSV-1 seropositive patients and in only $55-75 \%$ of $\mathrm{HSV}-2$ patients. In our opinion, these tests should be taken off the market. Since this is not a likely outcome in the near future, clinicians will have to be both well informed and persistent in determining that, in fact, their laboratory is applying the "new" assays based on HSV type specific glycoproteins gG-1 and gG-2.

Since most genitourinary medicine clinics work with reference laboratories, this subspecialty is likely to be among the first to have access to accurate testing. One hopes that practitioners of genitourinary medicine who are concerned with slowing the spread of sexually transmitted diseases will take the impending availability of accurate HSV type specific antibody tests as an opportunity to consider the value of such testing for patients. It is our opinion that once these tests hit the market, the reluctance of clinicians to fully face the issues of genital herpes will be met, in force, by patients whose sophistication in matters herpetic has been so dramatically revealed by Drs Fairley and Monteiro.

Professor, Laboratory Medicine,

RHODA L ASHLEY

Director, Diagnostic Virology Section,

University of Washington, Seattle,

Washington, USA

Professor, Laboratory Medicine and Medicine, LAWRENCE COREY

Head, Virology Division,

University of Washington,

and Director, Program in Infectious Diseases,

Fred Hutchinson Cancer Research Center,

Seattle, Washington, USA

1 Langenberg A, Benedetti J, Jenkins J, Ashley RL, Winter C, Corey L Development of clinically recognizable genital lesions among women previously identified as having "asymptomatic" herpes simplex virus type 2 viously identified as having "asymptomatic"
infection. Ann Intern Med 1989;110:882-7.

2 Koutsky L, Ashley R, Homes K, Stevens C, Critchlow C, Kiviat N, et al. The frequency of unrecognised type 2 herpes simplex virus infection among women: implications for the control of genital herpes. Sex Transm Dis 1990;17:90-4.

3 Cowan FM, Johnson AM, Ashley R, Corey L, Mindel A. Relationship between antibodies to herpes simplex virus and symptoms of herpes infection. F Infect Dis 1996;174:470-5.

4 Mertz G, Schmidt O, Jourden JL, Guinan ME, Remington ML, Fahnlander A, et al. Frequency of acquisition of first-episode genital infection with herpes simplex virus from symptomatic and asymptomatic source contacts. Sex Transm Dis 1985;12:33-9.

5 Mertz G, Coombs R, Ashley R, Jourden J, Remington M, Winter C, et al. Transmission of genital herpes in couples with one symptomatic and one Transmission of genital herpes in couples with one symptomatic and one

6 Mertz G, Benedetti J, Ashley R, Selke S, Corey L. Risk factors for sexual transmission of genital herpes. Ann Intern Med 1992;116:197-202.

7 Prober CG, Corey L, Brown ZA, Hensleigh PA, Frenkel LM, Bryson YJ, e $a l$. A consensus on the management of pregnant women with genita herpes simplex virus infections. Clin Infect Dis 1992;15:1031-8.

8 Svennerholm B, Olofsson S, Jeansson S, Vahlne A, Lycke E. Herpes simplex virus type-selective enzyme-linked immunosorbent assay with Helix pomatia lectin-purified antigens. F Clin Microbiol 1984;19:235-9.

9 Ashley R, Militoni J, Lee F, Nahmias A, Corey L. Comparison of Western blot (immunoblot) and glycoprotein G-specific immunodot enzyme assay for detecting antibodies to herpes simplex virus types 1 and 2 in human sera. F Clin Microbiol 1988;26:662-7.

10 Ashley R. Laboratory techniques in the diagnosis of herpes simplex infection. Genitourin Med 1993;69:174-83.

11 Ho DWT, Field PR, Irving WL, Packham DR, Cunningham AL Detection of immunoglobulin $M$ antibodies to glycoprotein $G-2$ by Western blot (Immunoblot) for diagnosis of initial herpes simplex virus type 2 genital infections. $\mathcal{f}$ Clin Microbiol 1993;31:3157-64.

12 Ho DWT, Field PR, Sjogren-Jansson E, Jeansson S, Cunningham AL Indirect ELISA for the detection of HSV-2 specific IgG and IgM antibodies with glycoprotein G (gG-2). $\mathcal{F}$ Virol Methods 1992;36:249-64.

13 Slomka MJ, Ashley RL, Cowan FM, Cross A, Brown DWG. Monoclonal antibody blocking tests for the detection of HSV-1 and HSV-2 specific humoral responses: comparison with Western blot assay. $\mathcal{F}$ Virol Methods 1995;55:27-35.

14 Green J, Kocsis A. Psychological factors in recurrent genital herpes. Genitourin Med 1997;73:253-8.

15 Cassidy L, Meadows J, Catalán J, Barton S. Are reported stress and coping style associated with frequent recurrence of genital herpes? Genitourin Med 1997;73:263-6.

16 Fairley I, Monteiro EF. Patient attitudes to type specific serological tests in the diagnosis of genital herpes. Genitourin Med 1997;73:259-62.

17 Oliver L, Wald A, Kim M, Zeh J, Selke S, Ashley R, et al. Seroprevalence of herpes simplex virus infections in a family medicine clinic. Arch Fam Med 1995;4:228-32.

18 Becker TM, Lee F, Daling JR, Nahmias AJ. Seroprevalence of and risk factors for antibodies to herpes simplex viruses, hepatitis B and hepatitis C among southwestern hispanic and non-hispanic white women. Sex Transm Dis 1996;23:138-44.

19 Wald A, Koutsky L, Ashley RL, Corey L. Genital herpes in a primary care clinic. Demographic and sexual correlates of herpes simplex type 2 infections. Sex Transm Dis 1997;24:149-55.

20 Brown ZA, Benedetti J, Ashley R, Burchett S, Selke S, Berry S, et al. Neonatal herpes simplex virus infection in relation to asymptomatic maternal infection at the time of labor. $N$ Engl $\mathcal{F}$ Med 1991;324:1247-52.

21 Brown ZA, Selke S, Zeh J, Kopelman J, Maslow A, Ashley RL, et al. The acquisition of herpes simplex virus during pregnancy. $N$ Engl $¥$ Med (in press).

22 Alexander D, Dinello R, Ashley R, Coit D, Corey L, George-Nascienento C, et al. Simultaneous use of glycoproteins $\mathrm{gB1}, \mathrm{gG1}, \mathrm{gD} 2$ and $\mathrm{gG2}$ as antigens for a type-specific serological assay to diagnose prior infection with HSV-1 or HSV-2. 96th ASM General Meeting, New Orleans, 1996 .

23 Ashley RL, Schnorenberg L, Wu L, Pickering J, Tu M. Enzyme immunoassy (EIA) for type-specific antibodies to herpes simplex virus 1

24 Ashley R, Cent A, Maggs V, Nahmias A, Corey L. Inability of enzym immunoassays to discriminate between infections with herpes simplex virus types 1 or 2. Ann Intern Med 1991;115:520-6. 